\title{
Estimativa de cargas residuais obtidas na ponta de estacas cravadas em solos porosos
}

\section{Estimate of the residual loads obtained in the end of piles driven in porous soils}

\author{
Stélio Maia Menezes ${ }^{1}$; David de Carvalho²; Paulo José Rocha de Albuquerque ${ }^{3}$
}

\section{Resumo}

\begin{abstract}
Na engenharia, geotécnica, o estudo da quantificação da carga residual verificada na ponta da estaca, após o final do primeiro carregamento do ensaio de prova de carga, salientou, em alguns trabalhos, a interpretação da curva carga versus o recalque de uma estaca. A construção de um modelo matemático para estudar tal fenômeno é baseado nas Relações de Cambefort. Neste trabalho, foram realizadas provas de carga em estacas pré-moldadas de concreto, confeccionadas especialmente para esta pesquisa. As mesmas possuem instrumentação instalada ao longo de todo o seu comprimento e nelas puderam ser medidas, por meio dos extensômetros de deformação, as cargas residuais embutidas na região da ponta da estaca.
\end{abstract}

Palavras-chave: Estacas. Provas de carga. Solos porosos.

\begin{abstract}
In the geotechnical engineering the study about the quantification of the residual loads in the pile end, after the end of the first loading of the load test attempt, highlighted some works on its interpretation in the curve load versus pile settlement. The construction of a mathematical model to study such a phenomenon is based on the Relations of Cambefort Precast-concrete piles were specially built for this research. They have special elements installed all along their length where the residual loads inlaid in the pile end region could be measured by means of deformation strain gauges.
\end{abstract}

Key words: Piles. Load tests. Porous soils.

\footnotetext{
1 Doutor em Engenharia Civil, Professor Adjunto, Departamento de Engenharia, UFLA, Lavras-MG, (35) 38291387, email: stelio@ufla.br

2 Pós-Doutor em Engenharia Civil, Professor Associado, Universidade Estadual de Campinas (UNICAMP), Campinas-SP

3 Doutor em Engenharia Civil, Professor Assistente Doutor, Universidade Estadual de Campinas (UNICAMP), Campinas-SP
} 


\section{Introdução}

As Leis de Cambefort (1964) representam, de forma matemática, as relações elementares de interação solo-estaca. Essas leis prevêem relações de tipo rígido-elástico-plástico, tanto para o atrito lateral quanto para a reação de ponta das estacas. Quando se submete, por exemplo, uma estaca a um segundo carregamento, numa prova de carga, surge na sua ponta uma carga residual que fica "aprisionada". Tal verificação foi feita por Décourt (1989) e Massad (1991-a), ao interpretarem provas de carga em estacas escavadas. Vésic (1977) já havia feito menção a este tipo de fenômeno em estaca escavada nas argilas rijas de Beaumont. A verificação da força "aprisionada" permite explicar o formato da curva carga-recalque relativa ao segundo carregamento em estacas submetidas a provas de carga.

Massad (1991-b) estabeleceu um modelo matemático baseado nas Relações de Cambefort (1964) postulando a carga residual "aprisionada" na ponta das estacas escavadas, ao término do primeiro e segundo carregamentos de uma prova de carga. A partir da idealização acima, põe-se a seguinte questão: as estacas pré-moldadas, após o término da cravação, apresentam tensões residuais de cravação embutidas na ponta. Desse modo, antes que se inicie o primeiro carregamento, já existe um valor "aprisionado", que deve ser quantificado e, por conseguinte, devidamente interpretado pela observação da curva carga versus recalque.

A diferenciação básica entre estacas escavadas e cravadas, no que refere à resolução deste problema, está na fase inicial de seus carregamentos. Nas estacas escavadas, devido ao processo de execução (moldagem in loco), não ocorrem cargas "aprisionadas" para o estabelecimento de sua primeira curva carga versus recalque. Somente no segundo carregamento, devido às cargas "aprisionadas" terem sido incorporadas, poder-se-á efetivamente quantificar tal valor.

Massad (1994) explica a causa do surgimento dessa carga sob a ponta de uma estaca cravada. "Ela ocorre porque a estaca é retida (devido à presença do atrito lateral), movendo-se de cima para baixo. Assim, ao aplicar-se um carregamento na estaca, a ponta irá reagir em conjunto com o atrito lateral, que necessita ser revertido. Dessa forma, não se altera o valor da carga máxima, e sim o formato da carga versus recalque, que sofrerá modificações".

O objetivo desta pesquisa é determinar, utilizando as Leis de Cambefort, a relação entre a reação da ponta da estaca com o seu deslocamento no solo, objetivando verificar a existência de cargas residuais embutidas na região da ponta da estaca, devido à sua cravação. Para tanto, foram instrumentadas três estacas de concreto colocando strain gauges, inseridos ao longo dos fustes, visando obter informações em diversos níveis de profundidade ao longo de seu comprimento no subsolo.

\section{Curva teórica carga versus recalque do solo}

O desenvolvimento da curva carga versus recalque teórica da estaca requer trechos bem definidos durante os carregamentos e descarregamentos da estaca. Os referidos trechos foram definidos em coordenadas $(0,3,4,5,6,7,8$ e 9 ), formando quatro pares de intervalos para o carregamento (0-3, 3-4, 4-5 e 5-6), e três para o descarregamento (6-7, 7-8 e 8-9), conforme mostrado na Figura 1. 


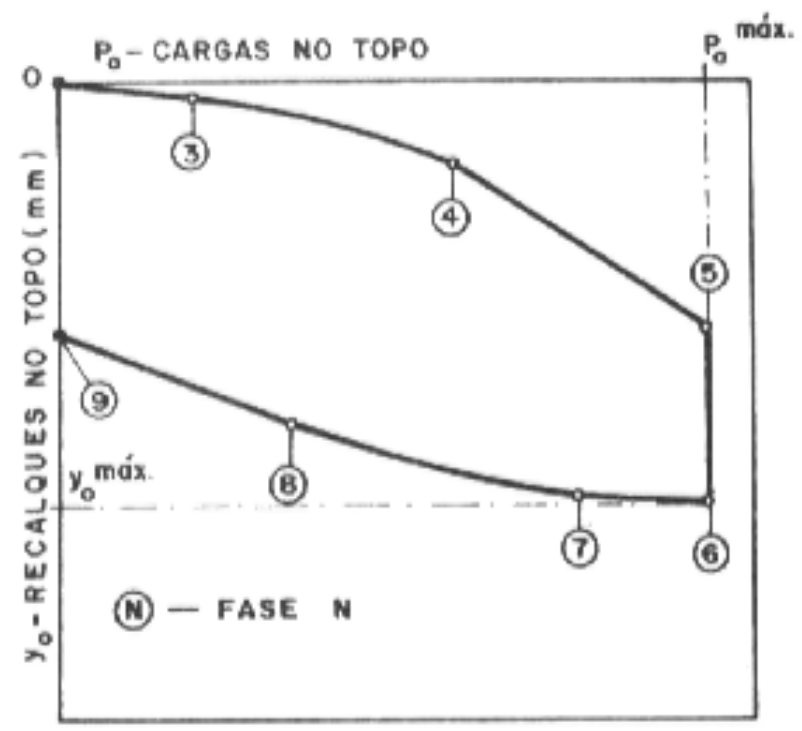

Figura 1-Curva carga versus recalque teórica (Massad, 1992).

- Trecho 0-3: definido como um trecho retilíneo, ocorrendo devido à fase pseudo-elástica de mobilização do atrito lateral, ao longo da reta inicial da primeira lei ou relação de Cambefort. O ponto 3 acusa o momento em que $\mathrm{o}$ atrito lateral atinge o seu máximo valor no topo da estaca;

- Trecho 3-4: representa ao avanço da "plena mobilização" do atrito lateral ao longo do fuste. Nesse intervalo observa-se um esboço de formato em curva ou ainda de uma parábola;

- Trecho 4-5: a relação carga versus recalque no topo da estaca volta a ser de forma linear. Nesse intervalo, surge a mobilização da resistência de ponta, correspondente ao trecho pseudo-elástico da segunda relação de Cambefort;

- Trecho 5-6: nesse trecho, chega-se ao valor de carga máxima total da estaca em que a reação de ponta atinge seu valor máximo;

- Trecho 6-7: corresponde, no descarregamento, ao primeiro trecho do estágio de carregamento da estaca (0-3), isto é, trata-se da fase pseudo-elástica da volta na relação de Cambefort;

- Trecho 7-8: analogamente, corresponde ao trecho 3-4, que representa um trecho curvilíneo, no sentido reverso da curva (para o descarregamento);
- Trecho 8-9: seguindo o caminho inverso do gráfico, ou seja, na curva de descarregamento, esse intervalo também se comporta como retilíneo - conforme se apresenta o trecho inicial da curva teórica.

\section{Material e métodos}

Com o intuito de realizar um estudo sobre fundações por estacas, in situ, foi utilizado um campo experimental de fundações, situado no campus da FEIS/UNESP, em local cujo subsolo é característico de várias cidades importantes do interior do estado de São Paulo, sendo representativo dos solos arenosos de alta porosidade encontrados em todo o CentroSul do Brasil. Nessa região, o solo tem uma formação inicialmente coluvionar (até 11 metros), de areia fina pouco argilosa e, em seguida, uma camada de solo aluvionar (em torno de 6 metros). Esses coluviões, com elevada porosidade, alcançam, em muitos locais, espessuras de até 15 metros, sendo comuns valores de até 8 metros.

Em razão de sua estrutura muito porosa, apresenta elevada compressibilidade, alta permeabilidade $\left(\mathrm{k}_{20}\right.$ $=10^{-3} \mathrm{~cm} / \mathrm{s}$ ), baixa resistência à penetração (SPT < 4 golpes e $\mathrm{QC}<2,5 \mathrm{MPa}$ ) e pequena capacidade de carga $\left(\sigma_{\mathrm{ADM}}<50 \mathrm{kPa}\right)$. Sua principal característica é a elevada colapsividade quando inundado após carregamentos, observando-se colapsos de até $15 \%$.

\section{Ensaios laboratoriais e de campo}

Foram realizadas sondagens SPT (com medição da resistência à penetração do solo e do torque máximo do solo), CPT (com medições das resistências de ponta, atrito lateral local e atrito lateral total do solo) e retirados blocos indeformados, nos quais se realizaram ensaios classificatórios e especiais no solo desta pesquisa. A Tabela 1 apresenta os resultados desses ensaios, enquanto a Tabela 2 mostra os valores dos ensaios de campo SPT e CPT (MENEZES, 1997). 
Tabela 1. Ensaios de caracterização e parâmetros de resistência.

\begin{tabular}{|c|c|c|c|c|c|c|c|c|c|}
\hline $\begin{array}{l}\text { Prof. } \\
(\mathrm{m})\end{array}$ & $\begin{array}{l}\mathrm{LL} \\
(\%)\end{array}$ & $\begin{array}{l}\text { LP } \\
(\%)\end{array}$ & $\begin{array}{c}\rho \\
\left(\mathrm{kN} / \mathrm{m}^{3}\right)\end{array}$ & Argila & $\begin{array}{l}\text { Gran } \\
\text { Silte }\end{array}$ & $\begin{array}{l}\text { ulometria }( \\
\text { Areia fina }\end{array}$ & $\begin{array}{l}\%) \\
\text { Areia média }\end{array}$ & $\begin{array}{c}\mathrm{C} \\
(\mathrm{kPa})\end{array}$ & $\begin{array}{c}\phi \\
\left({ }^{\circ}\right)\end{array}$ \\
\hline 1,0 & 23 & 14 & 16,0 & 29 & 08 & 59 & 04 & 0,0 & 32,2 \\
\hline 3,0 & 24 & 17 & 14,9 & 20 & 11 & 65 & 04 & 2,0 & 32,5 \\
\hline 5,0 & 27 & 16 & 14,8 & 33 & 08 & 56 & 03 & 2,0 & 33,3 \\
\hline 7,0 & 29 & 18 & 15,9 & 27 & 15 & 55 & 03 & 3,0 & 33,0 \\
\hline 9,0 & 28 & 16 & 18,4 & 28 & 12 & 57 & 03 & 16,0 & 30,3 \\
\hline 11,0 & 28 & 16 & 17,7 & 26 & 17 & 54 & 03 & 20,0 & 28,8 \\
\hline 13,0 & 29 & 17 & 18,8 & 30 & 15 & 52 & 03 & 20,0 & 28,8 \\
\hline 15,0 & 28 & 17 & 17,0 & 25 & 18 & 53 & 04 & 17,0 & 30,1 \\
\hline
\end{tabular}

$\mathrm{LL}=$ limite liquidez, $\mathrm{LP}=$ limite plasticidade, $\mathrm{c}=$ coesão, $\phi=$ ângulo de atrito, $\rho=$ massa específica do solo.

Tabela 2. Resultados dos ensaios de penetração SPT, SPTTe CPT.

\begin{tabular}{|c|c|c|c|c|c|}
\hline $\begin{array}{c}\text { Profundidade } \\
(\mathrm{m})\end{array}$ & $\begin{array}{c}\mathrm{N} \\
-\end{array}$ & $\begin{array}{c}\mathrm{T} \\
(\mathrm{N} . \mathrm{m})\end{array}$ & $\begin{array}{c}\mathrm{Q}_{\mathrm{C}} \\
(\mathrm{MPa})\end{array}$ & $\begin{array}{c}\mathrm{A}_{\mathrm{LL}} \\
(\mathrm{kPa})\end{array}$ & $\begin{array}{c}\mathrm{A}_{\mathrm{LT}} \\
(\mathrm{kN})\end{array}$ \\
\hline 1,0 & 6 & 32 & 4,7 & 60,7 & 3,7 \\
\hline 3,0 & 2 & 13 & 1,9 & 40,6 & 3,5 \\
\hline 5,0 & 4 & 31 & 3,4 & 66,3 & 4,3 \\
\hline 7,0 & 6 & 31 & 4,5 & 99,6 & 11,3 \\
\hline 9,0 & 7 & 45 & 4,8 & 114,0 & 17,5 \\
\hline 11,0 & 9 & 78 & 6,8 & 228,4 & 16,3 \\
\hline 13,0 & 10 & 82 & 6,7 & 314,5 & 28,2 \\
\hline 15,0 & 10 & 54 & 6,9 & 269,1 & 32,3 \\
\hline
\end{tabular}

$\mathrm{N}=$ número de golpes (SPT), $\mathrm{T}=$ momento torsor máximo (SPT-T)

$\mathrm{Q}_{\mathrm{C}}=$ resistência de ponta $(\mathrm{CPT}), \mathrm{A}_{\mathrm{LL}}=$ atrito lateral local, $\mathrm{A}_{\mathrm{LT}}=$ atrito lateral total.

\section{Características das estacas e instrumentação realizada}

Três estacas de concreto protendido foram préfabricadas e instrumentadas especialmente para esta pesquisa. Elas apresentaram os materiais característicos: aço com fyk $=1500 \mathrm{MPa}$ e concreto com fck $\geq 35 \mathrm{MPa}$, possuindo seção de $17 \times 17 \mathrm{~cm}^{2} \mathrm{e}$ comprimento de 13 metros. Em cada estaca foi deixada uma bainha galvanizada, com $40 \mathrm{~mm}$ de diâmetro, na qual foi instalada, posteriormente, toda a instrumentação. Essas estacas foram confeccionadas com oito estribos ao longo de todo seu comprimento, de maneira a garantir uma maior uniformidade e segurança estrutural.

A instrumentação foi constituída por barras de aço (com diâmetro de 12,5 mm), nas quais foram colocados extensômetros elétricos de resistência em ponte completa. Após colagem e ligação dos fios, instalou-se equipamento a proteção contra umidade e choque mecânico. Essas barras instrumentadas foram posteriormente inseridas no interior das bainhas, tendo sido feitas roscas em suas pontas, de maneira que, através de luvas, uma barra fosse ligada a outra até atingir-se o comprimento total da estaca (Figura 2). Após a colocação das barras instrumentadas, foi injetada nata de cimento no interior das bainhas, de maneira a haver uma maior solidarização com a estaca. Essa instrumentação permitiu obter os diagramas de transferência de carga estaca-solo. 


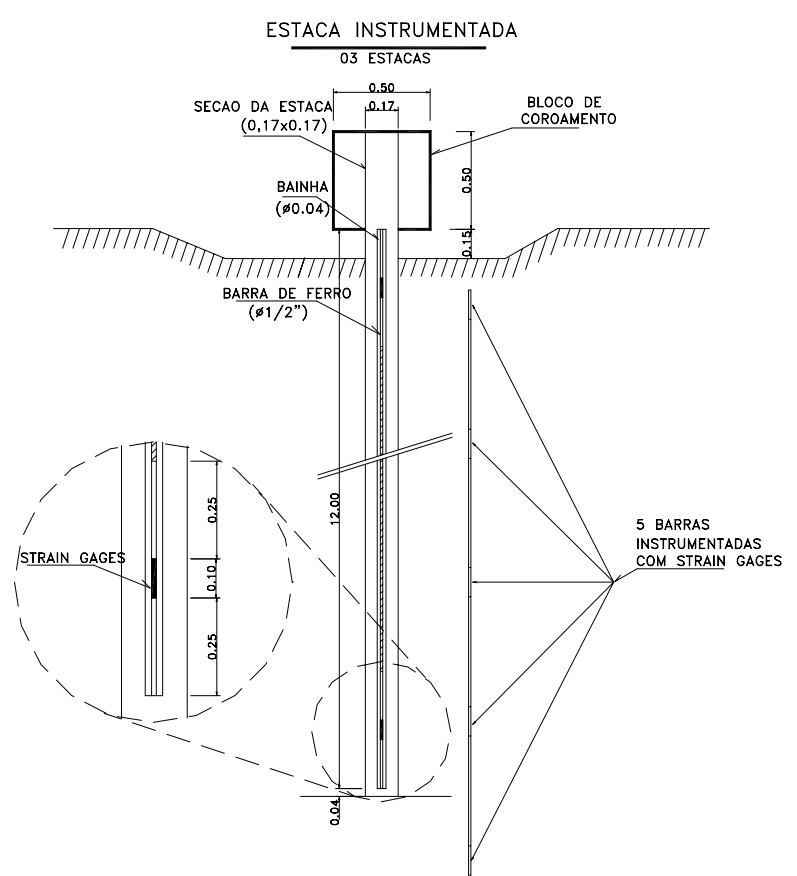

Figura 2. Detalhes da instrumentação nas estacas da pesquisa (medidas em metro).

\section{Provas de carga axiais nas estacas}

Conforme prescreve a NBR-12131/97 (provas de carga estáticas em estacas), foram efetuados carregamentos lentos, tipo Slow Maintained Load (SML), em estágios sucessivos, até que houvesse indícios de ruptura na interação estaca-solo. Os descarregamentos foram realizados em quatro estágios seguidos, com reduções de cargas iguais a 1/4 da carga máxima atingida para cada ensaio.

Iniciaram-se os ensaios aplicando-se estágios com carregamentos predeterminados (da ordem de $20 \%$ da carga máxima). As cargas aplicadas por meio de um macaco hidráulico tiveram valores monitorados por meio de uma célula de carga. Para cada carregamento, mediram-se os deslocamentos axiais da estaca por meio de quatro extensômetros (com precisão de $0,01 \mathrm{~mm}$ ) instalados diametralmente opostos sobre o bloco de coroamento. Adaptaramse duas vigas de madeira, com referências fixas, uma para cada face lateral do bloco, com apoios fora da zona de influência de carregamento, para fixação dos extensômetros.
Leituras de recalques foram realizadas imediatamente após a aplicação da carga e com os seguintes intervalos de tempo: 1, 2, 4, 8, 15 e 30 minutos, contados a partir do início do estágio e, posteriormente, a cada 30 minutos até atingir-se a estabilização. As leituras dos níveis de instrumentação da estaca foram lidas por meio do "indicador de deformações".

\section{Resultados e discussão}

As estacas 1, 2 e 3 receberam carregamentos axiais máximos de 270, 240 e 180 kN, atingindo-se deslocamentos de 44, 45 e $42 \mathrm{~mm}$, respectivamente. Devido a uma ocorrência de desnivelamento da viga de reação, a estaca 1 havia sido submetida a uma prova de carga anterior, que precisou ser interrompida na carga de $160 \mathrm{kN}$, para um recalque de 2,6 mm. Também a estaca 2 foi submetida a uma prova de carga anterior que precisou ser interrompida na carga de $210 \mathrm{kN}$ (tendo um recalque de 4,5 mm), devido ao arrancamento de uma das estacas de reação. $\mathrm{O}$ gráfico da Figura 3 representa as curvas cargarecalque para as três estacas, obtidas das provas de carga realizadas.

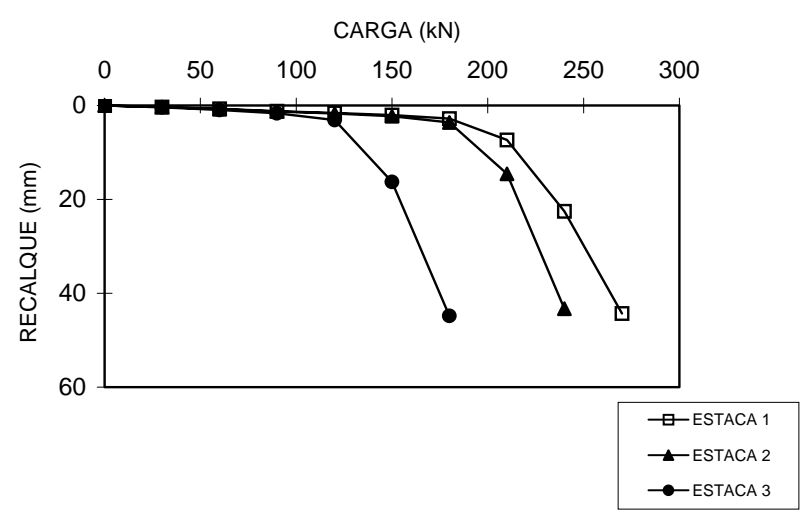

Figura 3. Curvas carga versus recalque para as três estacas ensaiadas

Nesse trabalho, foram medidas, por meio dos extensômetros de deformação, as cargas residuais embutidas na região da ponta da estaca. Com isso, puderam ser detectadas, in situ, as parcelas de atrito lateral e de reação de ponta - após o primeiro 
carregamento, mas, não foi possível obter tais valores imediatamente após sua cravação. A instrumentação das estacas foi instalada posteriormente; devido à precaução com os eventuais problemas de impacto e trepidação, ocasionados durante a cravação, somente foram instalados os extensômetros de deformação decorridos alguns dias após a realização desses trabalhos. Assim, tornou-se inviável medir as cargas residuais da estaca decorrentes das tensões de cravação ocasionadas pelo martelo do "bate-estacas".

Com base nas Leis de Cambefort, foram determinadas as curvas de atrito lateral versus deslocamento do fuste e de reação da ponta versus deslocamento da ponta para as três estacas. As Figuras 4, 5 e 6 apresentam as curvas de atrito lateral, enquanto as Figuras 7, 8 e 9 mostram os esboços dos valores relativos à reação de ponta da estaca.

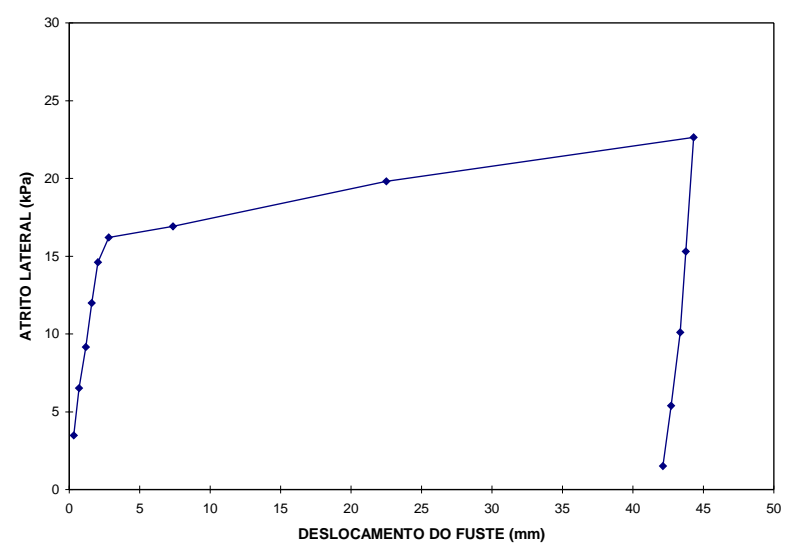

Figura 4-Curva atrito lateral versus deslocamento do fuste (estaca 1).

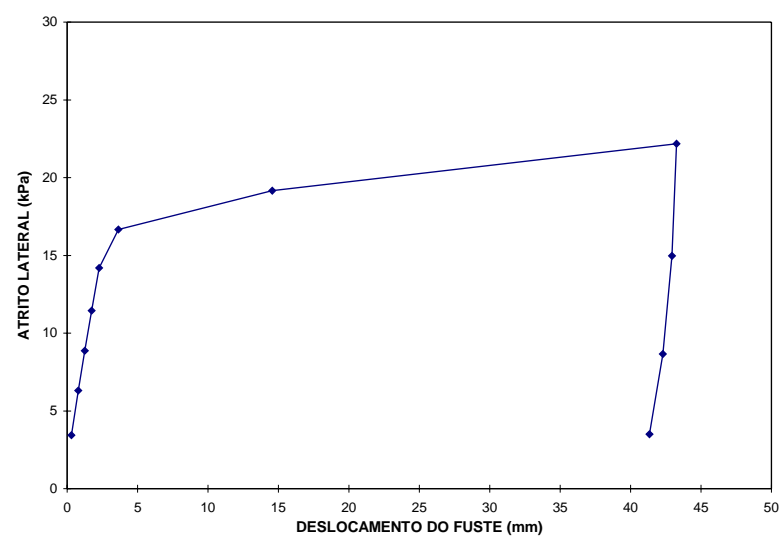

Figura 5 -Curva atrito lateral versus deslocamento do fuste (estaca 2).

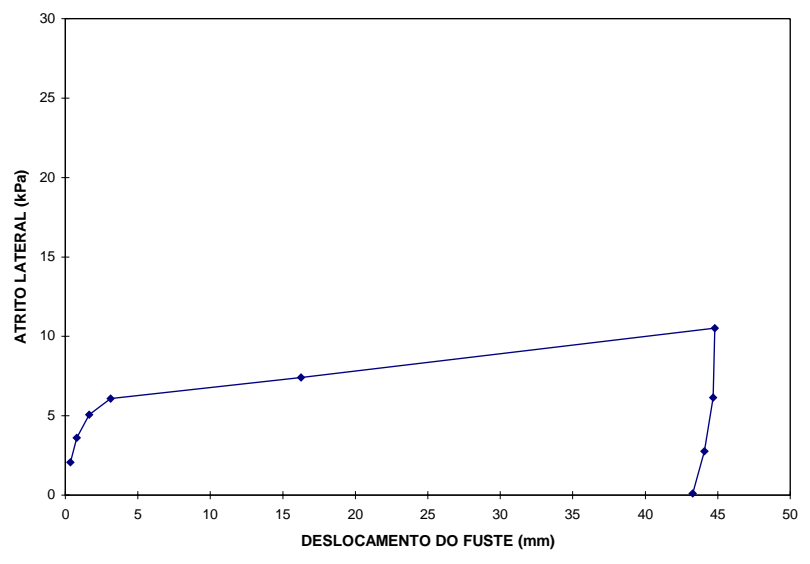

Figura 6-Curva atrito lateral versus deslocamento do fuste (estaca 3).

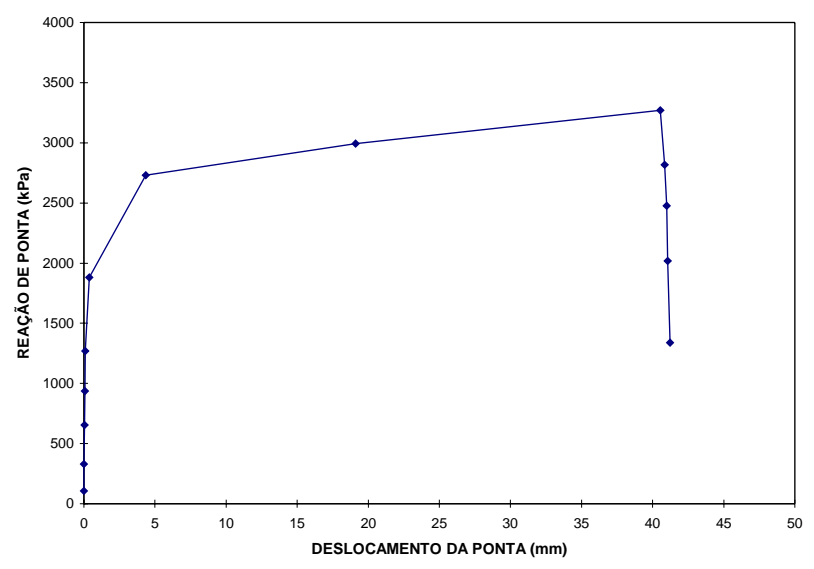

Figura 7-Curva reação de ponta versus deslocamento da ponta (estaca 1).

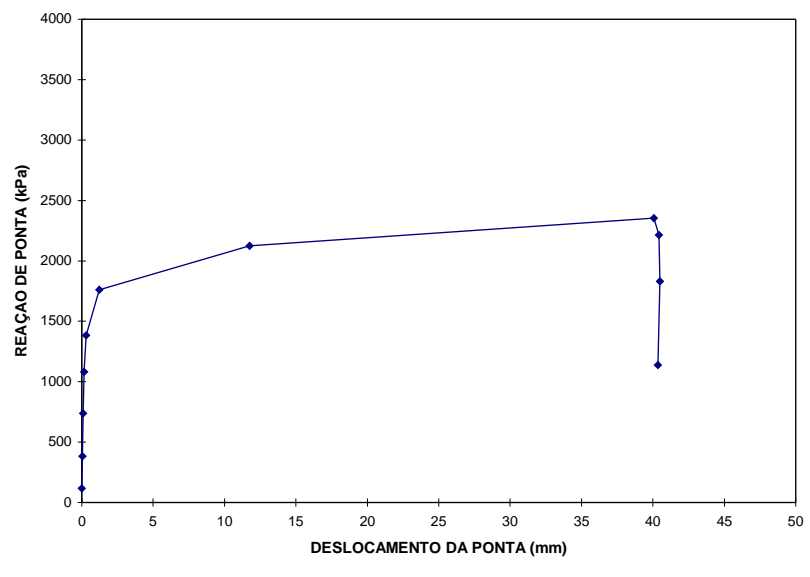

Figura 8-Curva reação de ponta versus deslocamento da ponta (estaca 2). 


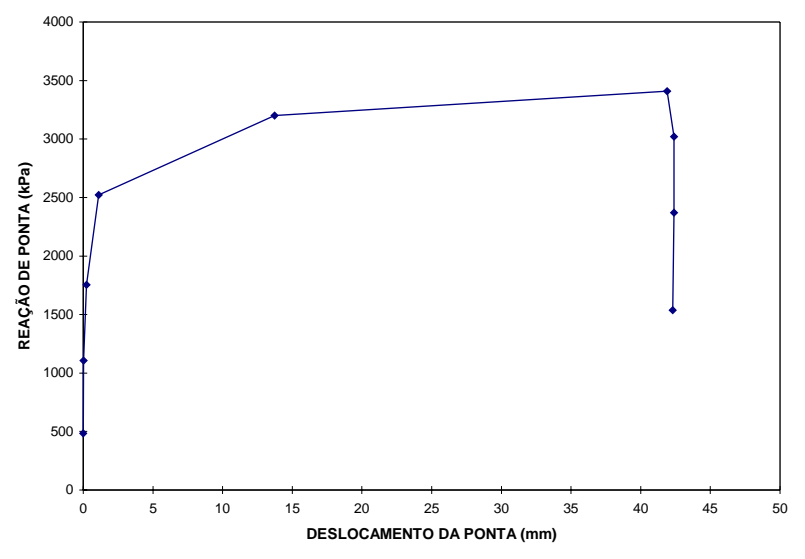

Figura 9-Curva reação de ponta versus deslocamento da ponta (estaca 3).

\section{Conclusões}

A existência de cargas residuais na ponta das estacas devido à cravação e a possibilidade dos primeiros carregamentos interrompidos terem introduzido alguma carga residual nas estacas 1 e 2, foram analisadas por meio das curvas "reação de ponta versus deslocamento da ponta", utilizando-se as relações de Cambefort, conforme proposto por Massad (1992). Para o primeiro carregamento, foram obtidos resultados de carga residual de 0,3 $\mathrm{MPa}, 1,4$ MPa e 1,5 MPa para as estacas 1, 2 e 3, respectivamente. Para o segundo carregamento (estacas 1 e 2 - que necessitaram de um segundo carregamento), os valores foram de 1,2 $\mathrm{MPa}$ e 1,1 $\mathrm{MPa}$, respectivamente.

$\mathrm{Na}$ estaca 2, o primeiro carregamento não introduziu nenhuma modificação no comportamento de ponta, ao passo que, na estaca 1, isso ocorreu. Essa observação na estaca 1 (quando a carga residual foi muito pequena no primeiro carregamento) corresponde ao momento em que o atrito lateral atingiu o valor máximo. Quando se procedeu ao segundo carregamento, a estaca 1 reagiu com uma carga de ponta bem superior, provocando a ocorrência de uma carga residual (resíduo do primeiro carregamento), de forma análoga ao fenômeno do pré-adensamento dos solos. Décourt (1989), que já havia verificado este comportamento em estações, denominou-a de "carga residual na base da estaca".
Sob o ponto de vista físico, a existência da carga residual significa que a ponta da estaca já está reagindo quando o atrito lateral começa a se desenvolver. Para as estacas da pesquisa (a compressão), cabe efetuar a reversão do atrito lateral que, logo após a cravação, atua de cima para baixo, "prendendo" a estaca no terreno e equilibrando a carga residual na ponta. Se o caso fosse de uma estaca tracionada, não haveria necessidade desta reversão, pois as cargas aplicadas agiriam no mesmo sentido da carga residual.

Além disso, é preciso levar em conta certos fenômenos, como a mobilização imediata de parte da resistência de ponta, antes da mobilização do atrito lateral, e a reversão deste mesmo atrito, pois a estaca está "aprisionada" no terreno logo após a sua cravação.

As estacas desta pesquisa apresentaram razoável carga de ponta, média de 3,0 MPa e bom atrito lateral, média de 38,8 kPa, em seu trecho inferior (até $9 \mathrm{~m}$ ). Para o trecho superior ( 9 a $12 \mathrm{~m}$ ), o atrito lateral médio $(12,1 \mathrm{kPa})$ foi inferior ao esperado, tomandose como base o valor médio $(28,7 \mathrm{kPa})$ já obtido para estacas escavadas moldadas in loco neste mesmo tipo de solo. Conclui-se que, para estas estacas prémoldadas implantadas nestes solos, deve-se considerar uma perda de atrito no trecho inicial da estaca.

As análises e observações de campo indicam que as vibrações de cravação provocam, pelo drapejamento da estaca, o seu descolamento do solo em um trecho que pode atingir alguns metros de profundidade.

Fica descartada a hipótese de alteração da ligação estaca-solo, no período entre a cravação das estacas e a realização das provas de carga, devido ao aumento e perda de umidade do solo (os ensaios foram conduzidos em época de chuvas) conduzindo a uma perda de atrito lateral no trecho inicial das estacas. Essa alteração é desprezada pelo fato de ela não ter ocorrido com outras estacas (tipo "apiloadas") também ensaiadas nesta pesquisa, as quais foram 
submetidas às mesmas condições de campo que as pré-moldadas. Devido aos vazios entre estaca-solo na parte superior das estacas pré-moldadas, pode ter havido uma maior facilidade de penetração de umidade em profundidade, não sendo possível, no momento, quantificar este efeito.

\section{Referências}

ABNT. NBR-12131/97: Provas de Carga Estáticas em Estacas. Rio de Janeiro, 1997.

CAMBEFORT, H. Essai sur le comportement en terrain homogéne des pieux isolés et des groupes de pieux. In: INSTITUT TECHNIQUE DU BATIMENT ET DES TRAVAUX PUBLICS. 1964, Paris. Annales...Paris, 1964. n. 204, p. 1478-1517.

DÉCOURT, L. Instrumented bored piles in residual soils. Suplementary contributions. In: INTERNATIONAL CONFERENCE ON SOIL MECHANICS AND FOUNDATION ENGINEERING, 12., 1989, Rio de Janeiro. Proceedings... Rio de Janeiro: ABMS, 1989.

MASSAD, F. Análise de transferência de carga em duas estacas instrumentadas, quando submetidas à compressão axial. In: SEMINÁRIO DE ENGENHARIA DE
FUNDAÇÕES ESPECIAIS, 2., 1991, São Paulo. Anais... São Paulo, 1991a. p. 235-244.

MASSAD, F. Estacas escavadas em compressão axial: Comportamento e parâmetros visando a estimativa dos recalques. In: SEMINÁRIO DE ENGENHARIA DE FUNDAÇÕES ESPECIAIS, 2., 1991, São Paulo. Anais... São Paulo, 1991b, p. 255-264.

MASSAD, F. Sobre a interpretação de provas de carga em estacas, considerando as cargas residuais na ponta e a reversão do atrito lateral. Parte I: Solos relativamente homogêneos. Solos e Rochas, São Paulo, v. 15, n. 2, p. 103-115, 1992.

MASSAD, F. Considerações sobre a forma da curva carga-recalque de estacas solicitadas axialmente. São Carlos: Escola de Engenharia de São Carlos, 1994.

MENEZES, S. M. Análise do comportamento de estacas pré-moldadas em solo de alta porosidade do interior do estado de São Paulo. 1997. 377 p. Tese (Doutorado em Engenharia Civil) - Escola Politécnica, Universidade de São Paulo, São Paulo, 1997.

VÉSIC, A. S. On the significance of residual loads for load response of piles. In: INTERNATIONAL CONFERENCE ON SOIL MECHANICS AND FOUNDATION ENGINEERING, 9., 1977, Stockholm. Proceedings... Stockolm, 1977. v. 3, p. 373-379. 